\title{
EL PROCEDIMIENTO DE ELECCIÓN DEL PARLAMENTO EUROPEO: UN REFLEJO DE LA HISTÓRICA DOBLE VISIÓN DEL PROCESO DE INTEGRACIÓN Y LA DIFICULTAD DE LLEGAR A CONSENSOS
}

\author{
COVADONGA FERRER MARTÍN DE VIDALES \\ Profesora Contratada Doctora interina de Derecho Constitucional \\ Universidad Complutense de Madrid
}

TRC, núm. 45, 2020, pp. 533-556

ISSN 1139-5583

SUMARIO

I. Introducción. II. La elección del Parlamento Europeo: del deseo de un procedimiento uniforme a la adopción de unos principios comunes. III. El sistema electoral británico para las elecciones al Parlamento Europeo: del tradicional sistema mayoritario a la adopción de un sistema de tipo proporcional. IV. Conclusiones.

\section{INTRODUCCIÓN}

El Parlamento Europeo, institución que representa a los ciudadanos de la Unión y que, por tanto, puede decirse que es la más democrática de todas las que integran su marco institucional, tiene sus orígenes en los Tratados constitutivos firmados en los años cincuenta y a lo largo del proceso de integración ha ido incrementando sus competencias ${ }^{1}$ hasta situarse actualmente prácticamente en plano de igualdad con el Consejo ${ }^{2}$.

1 El propio Parlamento Europeo desde un primer momento demandó una ampliación de sus poderes y un trato de igualdad con el Consejo en todos los ámbitos de competencia legislativa y presupuestaria de la Unión, a fin de que la Comunidad tuviese un proceso de toma de decisiones más eficiente y democrático. Así, por ejemplo, puede señalarse el informe Vedel que enfatizaba la necesidad de ampliar las competencias del Parlamento para reforzar el elemento democrático en la Comunidad. Vedel Rapport, Rapport du groupe ad hoc pour l'examen du problème de l'accroissement des compétences du Parlement européen du 25 mars 1972, Bulletin des Communautés européennes. 1972, n Supplément 4/72, p. 36-38, pp. 20 y ss. Sobre la historia del Parlamento Europeo puede consultarse a Romo García, M., Historia del Parlamento Europeo (1950-2000), URJC, servicio de publicaciones, Madrid, 2001.

2 Prácticamente porque, todavía, siguen existiendo competencias plenamente reservadas al Consejo y quedan bases jurídicas que requieren la unanimidad del mismo, lo cual sitúa a un solo Estado con el mismo 
Como es sabido, cada Tratado constitutivo preveía la creación de su propia Asamblea, compuesta por delegados de los Parlamentos nacionales que serían designados según las normas y mecanismos fijados en cada Estado miembro, pero ya desde el Tratado CECA se contemplaba la posibilidad de elecciones directas a la Asamblea Parlamentaria y el Tratado CEE introducía la posibilidad de establecer un procedimiento uniforme de elección por sufragio directo ${ }^{3}$. Procedimiento que, desde un primer momento, no fue posible establecer adoptándose finalmente unos principios comunes a todos los Estados miembros.

Con el tiempo, se ha ido produciendo una convergencia cada vez mayor ${ }^{4}$, aunque sigue sin haber unas elecciones europeas que se celebren al mismo tiempo en todos los Estados miembros y conforme a un procedimiento electoral uniforme establecido completamente por las normas de la Unión. Se mantiene una sucesión de elecciones nacionales, que se rigen por los mencionados principios comunes dentro de un período de tiempo limitado ${ }^{5}$. Y los partidos y las campañas siguen centrándose principalmente en asuntos domésticos, por lo que se ha acuñado para las elecciones europeas el término de elecciones nacionales de segundo orden («second-order national lections) ${ }^{6}$. El nuevo sistema de los «cabezas de lista»o «spitzenkandidaten» tampoco parece haber logrado los resultados esperados a este respecto ${ }^{7}$.

El presente trabajo tiene por objeto realizar un breve examen de los principales motivos por los que no fue posible adoptar un procedimiento electoral uniforme ${ }^{8}$

poder formal que todo un Parlamento. Sigue habiendo, por tanto, una clara preponderancia de Consejo y Consejo Europeo, instituciones que representan los intereses de los Estados miembros, que ocupan una posición central, por lo que se ha señalado que el Parlamento Europeo no ocupa a nivel de la Unión una posición similar a la que tienen sus homónimos nacionales en sus respectivos Estados. Matía Portilla, F.J., Parlamentos Nacionales y Derecho Comunitario Derivado, CEPC, Madrid, 1999, pp. 62-63; MARTínez Sierra, J.M., «La Constitución Europea. ¿Qué papel cumple en este momento? Una lectura crítica» Documentación Social $n^{\circ} 134$, 2004 , p. 52.

3 Vid. arts. 20 y 21 Tratado CECA (redacción original); arts. 138.1 y 138.3 Tratado CEE (redacción original); y arts. 3.1 y 108 Tratado CEEA (redacción original)

4 Un análisis de los elementos más relevantes de los principios comunes para la elección del Parlamento Europeo en Pascua Mateo, F., «Eligiendo al Parlamento Europeo: principios comunes a los Estados miembros», CEFLegal: revista práctica de derecho. Comentarios y casos prácticos, $\mathrm{n}^{\circ} 225,2019$, pp. 91-130.

5 Mellado Prado, P., «El sistema de representación del Parlamento Europeo cuestionado: la ausencia de un procedimiento electoral uniforme», TRC, $\mathrm{n}^{\circ} 33,2014$, p. 220.

6 Ya en 1980 Reif y Schmitt definieron las elecciones europeas como unas elecciones adicionales nacionales de segundo orden, que venían determinadas más por divisiones nacionales que por las alternativas originadas a nivel de la Comunidad Europea. Reif, K., Schmitт, H., «Nine second-order national elections. A conceptual framework for the analysis of European elections results», European Journal of Political Research 8, 1980, pp. 3-44.

7 Hовоlт, S.B., «A vote for the President? The role of Spitzenkandidaten in the 2014 European Parliament elections», Journal of European Public Policy, Volume 21, Issue 10, 2014, pp. 1536-1537.

8 Los distintos informes que se examinan en el presente trabajo, consideran como elementos del mencionado procedimiento, que pueden ser armonizados en busca de una mayor uniformidad, el sistema electoral, el derecho de voto, el derecho de sufragio pasivo, el tipo de circunscripción, etc. Vid, por ejemplo, Seitlinger Report, Report drawn up on behalf of the Political Affairs Committee on a draft uniform electoral procedure for the election of Members of the European Parliament, European Parliament Working Documents 
para las elecciones al Parlamento Europeo, estableciéndose finalmente unos principios comunes a todos los Estados miembros como se ha adelantado. A dicho fin, se analizan en primer lugar las distintas propuestas presentadas al respecto desde los orígenes del proceso de integración hasta la actualidad, centrándonos en las dificultades surgidas para llegar a consensos y que llevaron a optar por una aproximación por etapas. A continuación, se lleva a cabo un examen particular del caso del Reino Unido como uno de los motivos (aunque no el único) que imposibilitó en su momento la adopción de dicho procedimiento uniforme - abordando en concreto por qué se optó en dicho país por mantener inicialmente el tradicional sistema mayoritario y y finalmente se abandonó el mismo-. La evolución en el procedimiento de elección al Parlamento Europeo como se verá, no difiere de lo que ha sido la tradicional evolución del proceso de integración, con las diferentes visiones de cómo debe avanzarse y las señaladas dificultades para llegar a consensos, que han conllevado que los avances hayan tenido que realizarse paso a paso.

\section{LA ELECCIÓN DEL PARLAMENTO EUROPEO: DEL DESEO DE UN PROCEDIMIENTO UNIFORME A LA ADOPCIÓN DE UNOS PRINCIPIOS COMUNES}

Como se ha adelantado, el Tratado CECA preveía la posibilidad de elecciones directas a la Asamblea Consultiva y el Tratado CEE introducía, además, la posibilidad de elección de la Asamblea Parlamentaria de acuerdo con un procedimiento uniforme en todos los Estados miembros ${ }^{10}$. Desde entonces, diversos informes se sucedieron intentando establecer el mencionado procedimiento, sin que finalmente se consiguiera adoptar el mismo. Dichos informes pueden dividirse en dos períodos: los presentados hasta las primeras elecciones europeas

1981-1982, Document 1-988/81/B-C, p. 3. O la opinión del Comité de Asuntos Jurídicos y Derechos de los Ciudadanos sobre el informe Bocklet. Bocklet Report, Report drawn up on behalf of the Political Affairs Committee on a draft uniform electoral procedure for the election of Members of the European Parliament, European Parliament Working Documents 1985-86, Document A 2-1/85, 22 March 1985, p. 23. No obstante, no se realiza un análisis detallado de cada uno de dichos elementos, pues excede del objeto del presente trabajo, que como se señala se centra en determinar los motivos que no permitieron adoptar un procedimiento uniforme.

9 También Francia mantuvo un sistema mayoritario hasta las elecciones al Parlamento Europeo de 1999. Una explicación del mismo puede consultarse en BREw, D.A., «Characteristics on major voting systems and the national voting systems of the nine» en Sasse, Brew, Georgel, Hand, Huber and van den Berghe, The European Parliament: Towards a Uniform Procedure for Direct Elections, European University Institute, Florence: Badia Fiesolana, 1981, pp. 59-61.

10 La redacción final del artículo 138 del Tratado CEE se debe a una propuesta presentada por Italia durante los trabajos preparatorios conducentes al mismo, que fue la fórmula de compromiso aceptada ya que daba más tiempo a los Estados antes de la introducción de las elecciones directas. Vid. BERGHE, G. VAN DEN, «What is a 'Uniform Procedure'?» en Sasse, Brew, Georgel, Hand, Huber and van den Berghe, The European Parliament: Towards a Uniform Procedure for Direct Elections, European University Institute, Florence: Badia Fiesolana, 1981, pp. 7-10. 
directas, y los sucedidos desde las mismas hasta la actualidad. Pasamos a exponerlos a continuación.

\section{1. ¿Celebración de elecciones directas o establecimiento de un procedimiento electoral uniforme? Las primeras propuestas}

Durante los primeros años del proceso de integración europeo, el dilema principal era cómo dar cumplimiento al mandato establecido por los Tratados, es decir, la realización de elecciones directas — sobre la base de las disposiciones nacionales - o el establecimiento de un procedimiento electoral uniforme, y cuál de las dos opciones realizar en primer lugar ${ }^{11}$.

Ante la dificultad de lograr un consenso con respecto al procedimiento electoral uniforme, la celebración de elecciones directas se convertiría en la prioridad fundamental para la Asamblea ${ }^{12}$, que veía en las mismas la vía para reforzar su legitimidad democrática y conseguir más competencias ${ }^{13}$. Pese a ello, la Asamblea, en cumplimiento del mandato establecido en el artículo 138.3 del TCEE, perseguiría el objetivo del establecimiento de un procedimiento electoral uniforme durante las siguientes décadas a través de diversos informes, en los que se debatieron cuestiones como el número de escaños del Parlamento y su distribución, la uniformidad del sistema electoral, el mantenimiento del doble mandato, o la introducción de un principio de proporcionalidad ${ }^{14}$.

El primero de estos informes es el conocido como informe Dehousse de 1960, que adoptaba un enfoque moderado, con una interpretación flexible de la noción «procedimiento uniforme» en el sentido de que uniformidad no era sinónimo de

11 KARK, K.S., A new uniform voting system for elections to the European Parliament?, PhD thesis, Cardiff University, Cardiff Law School 2013, pp. 112-113. Disponible en https://orca.cf.ac.uk/48286/12/PhDThesisKorrektur.pdf

12 KARK, K.S., op. cit.., p. 121. Los distintos documentos relativos a esta esta etapa pueden consultarse en Parlament Européen, Pour l'élection du Parlement européen au suffrage universal direct, Recueil de documents, Direction Génerale de la Documentation Parlementaire et te l'information, Decembre 1969; y EuROPEAN PARLIAMENT, Elections to the European Parliament by direct universal suffrage, Secretariat, Directorate-General for Research and Documentation, July 1977. Un detallado análisis de esta primera etapa que llevaría a las primeras elecciones directas puede encontrarse en PIODI, F., «Towards direct elections to the European Parliament», CARDOC Journals n 4, March 2009.

13 Alonso de León, S., «Crónica de la reforma electoral europea», Revista de las Corte Generales, N 106, Primer semestre (2019), p. 233. El informe Teitgen de 1954, pese a versar sobre los poderes de control de la Asamblea y su ejercicio, ya reconocía que la elección por sufragio universal de sus miembros contribuiría a incrementar la autoridad moral y política y la eficacia de la Comunidad. Teitgen Rapport, fait au nom de la Commission des Affaires Politiques et des Relations extérieures de la Communauté sur les pouvoirs de contrôle de l'Assemblée Commune et leur exercice, Document no 5 1954-1955, noviembre 1954, para. 20. El informe Vedel de 1972 (centrado en la ampliación de las competencias del Parlamento Europeo), y el informe Tindemans de 1975, volvían a hacer énfasis en esta idea. Vedel Rapport, op. cit., pp. 36-38. Tindemans Report, Bulletin of the European Communities, Supplement 1/76, p. 29.

14 Alonso de León, S., op. cit., pp. 233-234. 
identidad $^{15}$. Asimismo, proponía una realización por etapas, con una primera en la que el procedimiento electoral seguiría estando fijado por las normas nacionales de los Estados miembros, pero conforme a los principios generales fijados por la convención ${ }^{16}$, y una segunda en la que la propia Asamblea establecería las disposiciones para la elección de sus miembros conforme a un procedimiento «lo más uniforme posible» ${ }^{17}$. Aproximación que se mantuvo en el siguiente informe elaborado por Patijn ${ }^{18}$, que fijaba como plazo para el establecimiento del mencionado procedimiento el año 1980, debiendo para entonces el Consejo adoptar las disposiciones adecuadas y recomendar a los Estados miembros su adopción de conformidad con sus respectivas normas constitucionales ${ }^{19}$.

Las dificultades de establecer un sistema electoral uniforme aceptable para todos los Estados miembros — teniendo en cuenta sus diferentes tradiciones constitucionales comunes-, la propia dificultad de escoger un sistema electoral por la influencia del mismo en la propia composición de la Asamblea, y el temor a que la falta de acuerdo al respecto retrasase la celebración de elecciones direc$\operatorname{tas}^{20}$, pesaron en la opción por el sistema flexible y por etapas, sin adoptar desde un primer momento un procedimiento uniforme. Sin embargo, la falta de acuerdo a nivel de los Estados miembros impidió la adopción de ninguna de estas dos primeras propuestas.

Esta división entre el establecimiento de unos principios comunes, por un lado, o de un sistema electoral uniforme, por otro, se mantendría en los distintos

15 Berghe, G. van den, op. cit., p. 11.

16 Dehousse Rapport, fait au nom de la Commission des affaires politiques et des questions institutionnelles sur l'élection de l'Assemblée parlementaire européenne au suffrage universel direct, Assemblée Parlementaire Européenne, Documents de Séance 1960-1961, Document 22, 30 Avril 1960, p. 30. Debe puntualizarse que el informe es complejo, pues contiene cuatro informes al respecto: el introductorio realizado por Dehousse como ponente, uno sobre composición de la Asamblea realizado por Faure, otro sobre las cuestiones relativas a la elección del sistema electoral a cargo de Schuijr; un cuarto sobre la representación de los países y territorios de ultramar realizado por Metzger y un último informe sobre los aspectos de la política informativa de cara a preparar al público para las elecciones redactado por Carboni. PIODI, F., op.cit., p. 18.

17 Ibíd. Aunque la propuesta del informe Dehousse sería adoptada por resolución de la Asamblea de 2 de junio de 1960, la preferencia del general De Gaulle por una aproximación más intergubernamental frenaría la adopción de ningún tipo de recomendación a nivel del Consejo. La postura de Francia cambiaría con el acceso a la Presidencia de Valéry Giscard d'Estaing. Su apoyo al desarrollo de la integración europea, así como el que también proporcionaría Helmut Schmidt (que susituía a Willy Brandt), daría un nuevo impulso al Parlamento Europeo que conduciría a la adopción del siguiente informe elaborado por Patjin. Vid. Costa, O., The bistory of European electoral reform and the Electoral Act 1976. Issues of democratisation and political legitimacy, European Parliament History Series, EPRS, October 2016, p. 18.

18 Que volvía a recordar que ya en 1960 se había concluido que «procedimiento uniforme» no era sinónimo de «sistema electoral uniforme». Patijin Rapport, Rapport du 13 janvier 1975 relatif à l'adoption d'un projet de convention instituant l'élection des membres du Parlement européen au suffrage universel direct, Parlement européen, Documents de séance 1974-1975. 13.01.1975, nº Document 368/74, pp. 13-14.

19 Vid. Artículo 7 del Proyecto de convención para las elecciones directas al Parlamento Europeo. Resolution on the adoption of a draft convention introducing elections to the European Parliament by direct universal suffrage, OJ C 32/15, 11/02/1975.

20 Vid. Dehousse Rapport, pp. 27-28; Vedel Rapport, pp. 36-38. 
informes posteriores. En todos ellos puede observarse, como señala Kark, la doble tensión que ha existido siempre a lo largo de todo el proceso de integración y las distintas visiones sobre el mismo: por parte del Parlamento, que puede decirse ha perseguido siempre un modelo más federal, y por parte de los Estados miembros, que han seguido un modelo más intergubernamental ${ }^{21}$. También puede observarse, como señala Costa, que en todos se realiza una aproximación técnica al problema, teniendo en cuenta la oportunidad y la importancia de la elección por sufragio universal directo, pero sin discutir cuestiones más abstractas o teóricas como la noción de pueblo europeo o de representación a nivel supranacional ${ }^{22}$.

\section{El procedimiento electoral vigente: unos principios comunes}

El proyecto de Convención elaborado por Patijn en 1975, al que se ha hecho referencia en el apartado anterior, serviría de base para los trabajos y discusiones que llevarían finalmente a la adopción por el Consejo de Ministros del Acta Electoral Europea el 20 de septiembre de $1976^{23}$, mediante la que finalmente se posibilitó la realización de las primeras elecciones directas al Parlamento Europeo ${ }^{24}$.

A partir de este momento, continuaron los intentos del Parlamento Europeo por establecer un procedimiento electoral uniforme a través, nuevamente, de distintos informes que tampoco lograron la unanimidad en el Consejo ${ }^{25}$. Los principales obstáculos se encontraban en la distribución de escaños y en el mantenimiento del sistema mayoritario por parte del Reino Unido (el denominado first past the

21 KARK., K. S., op. cit., p. 116 y 119.

22 Vid. Costa, O., op. cit., pp. 15 y 23.

23 Decision 76/787/ECSC, EEC, Euratom of the representatives of the Member States meeting in the council relating to the Act concerning the election of the representatives of the Assembly by direct universal suffrage, y Act concerning the election of the representatives of the Assembly by direct universal suffrage. OJ L 278, 8.10.1976. El Acta mantenía que hasta la entrada en vigor del procedimiento electoral uniforme que debería elaborar el Parlamento Europeo se mantendrían las disposiciones establecidas a nivel nacional con sujeción a las disposiciones del Acta (art. 7), pero sin establecer ningún plazo específico para el establecimiento de aquél.

24 Ya en la Cumbre celebrada en 1974 los Jefes de Estado y de Gobierno habían señalado que la elección del Parlamento Europeo por sufragio universal directo debía ser realizada lo antes posible. Final communiqué of the meeting of heads of Government of the Community, Paris, 9 and 10 December 1974. OJ No. 12, 1974. Y en la cumbre de 1975 en Roma acordaron que las elecciones tendrían lugar en mayo o junio de 1978. Conclusions of the meeting of the European Council, Rome, 1-2 December 1975, p. 5.

25 El informe Seitlinger de 1982 no llegaría a la unanimidad necesaria en el Consejo, el informe Bocklet preparado entre 1984 y 1989 se toparía con la falta de consenso necesario esta vez en el propio Parlamento Europeo que no adoptó ningún texto, y el informe De Gutch tampoco recibiría respuestas por parte del Consejo. Vid. Corbett, R.; Jacobs, F., Shackleton, M., The European Parliament, John Harper Publishing, 2011, p. 15; Anastassopoulos Report, Report on a proposal for an electoral procedure incorporating common principles for the election of Members of the European Parliament, Parlamento Europeo, Documento A4-0212/98, pp. 10-14. 
post system). La ampliación a nuevos Estados miembros, con sus respectivos sistemas electorales, añadía más complejidad a la situación ${ }^{26}$.

Estos sucesivos informes optaron asimismo por la aproximación por etapas en la búsqueda del necesario acuerdo con respecto a las cuestiones esenciales, adoptando nuevamente una interpretación flexible del concepto de «uniformidad», en el sentido de que el mismo no requería una identidad y uniformidad completa del procedimiento electoral en todos los Estados miembros sino solo una armonización de los principales elementos del mismo (sistema electoral, derecho de voto y derecho a ser elector y elegible $)^{27}$.

Por lo que respecta al sistema electoral ${ }^{28}$, el sistema de representación proporcional es el que se planteaba como mejor opción al ser ya el utilizado en la mayoría de Estados miembros. Así, por ejemplo, el informe Seitlinger proponía un modelo híbrido que combinase las ventajas del voto personal con aquellas de la representación proporcional ${ }^{29}$; recogiéndose en la propuesta de resolución finalmente remitida al Parlamento Europeo la elección de los representantes de los Estados miembros por representación proporcional, dividiéndose los Estados miembros en circunscripciones plurinominales en las que se elegirían un mínimo de tres y un máximo de quince representantes ${ }^{30}$. El informe Bocklet, proponía la proporcionalidad en circunscripciones plurinominales o en una única circunscripción ${ }^{31}$, planteando la posibilidad de dar a los Estados miembros una excepción temporal para aplicar el sistema acordado. Y el informe De Gucht llevaría a la adopción por el Parlamento Europeo en marzo de 1993 una nueva resolución sobre el proyecto de procedimiento electoral uniforme en la que la premisa principal era la armonización de los principales elementos del procedimiento

26 KARK., K. S., op. cit., p. 129.

27 Vid. Bocklet Report, op. cit., p. 4; De Gucht Report, Interm report of the Committee on Institutional Affairs on the European Parliament's guidelines for the Draft Uniform Electoral Procedure for Members of the European Parliament, 29 May 1991, European Parliament Session Documents, A3-0152/91.

28 Entendido, como señalaba el informe Steiglinger, como el sistema por el que los resultados de una elección determinan la composición de un parlamento. Es decir, cómo los votos se transforman en escaños. Vid. Seitlinger Report, Report drawn up on behalf of the Political Affairs Committee on a draft uniform electoral procedure for the election of Members of the European Parliament, European Parliament Working Documents 1981-1982, Document 1-988/81/B-C, p. 4. Sistema que, como ya señalaba Schuijt en su informe de 1960 sobre las cuestiones relativas al régimen electoral para la elección de la Asamblea Europea, tiene no sólo una influencia en la composición de un Parlamento sino también en la vida de los partidos políticos. Vid. Parlement Européen, Pour l'élection du Parlement européen au suffrage universal direct, op. cit., p. 48. Sobre sistemas electorales, vid. Vallés, J. M.; Bosch, A., Sistemas electorales y gobierno representativo, Ariel, Barcelona, 1997; Garrote de Marcos, M., El ámbito territorial de las elecciones al Congreso de los Diputados en España. Congreso de los Diputados, Madrid, 2007.

29 Vid. Seitlinger Report (Document 1-988/81/B-C), op. cit., p. 6.

30 Artículo 2 de la propuesta de resolución del Parlamento Europeo contenido en el informe final aprobado por el Comité. Vid. Seitlinger Report, Report drawn up on behalf of the Political Affairs Committee on a draft uniform electoral procedure for the election of Members of the European Parliament, European Parliament Working Documents 1981-1982, Document 1-988/81/A, 10 February 1982.

31 Artículo 4 de la propuesta de resolución del Parlamento Europeo contenida en el informe final aprobado por el Comité de Asuntos Políticos. Vid. Bocklet Report, op. cit., p. 4. 
electoral, en especial el principio de representación proporcional ${ }^{32}$, contemplándose asimismo una excepción (principalmente por Reino Unido) para aplicar el sistema de elección por circunscripciones uninominales para las dos terceras partes de los escaños correspondientes al Estado miembro, distribuyendo el resto de escaños del mismo de forma que la distribución global de los mandatos de ese Estado miembro correspondiese proporcionalmente al total de votos emitidos ${ }^{33}$.

Sin embargo, no sería hasta 1997 cuando, a raíz de dos importantes cambios, se produciría un avance importante. Por un lado, la llegada de laboristas (gracias al pacto con los liberal-demócratas) al gobierno en el Reino Unido, que llevaría como se examinará en el siguiente apartado a la reforma de su sistema electoral y a la introducción del sistema proporcional en circunscripciones regionales ${ }^{34}$. Por otro, la reforma introducida por el Tratado de Ámsterdam en el artículo 138 del TCE $^{35}$, que posibilitaba que la elección del Parlamento Europeo pudiese realizarse bien por un «procedimiento uniforme en todos los Estados miembros», bien «de acuerdo con principios comunes a todos los Estados miembros» ${ }^{36}$.

La posibilidad del establecimiento de principios comunes ya se venía planteando en los últimos informes del Parlamento Europeo ${ }^{37}$, que como se ha señalado no proponían una total uniformidad del procedimiento sino de los elementos esenciales o principales del mismo. La nueva posibilidad introducida por el Tratado de Ámsterdam abría la puerta a intentar lograr un consenso en el Consejo, donde el requisito de la unanimidad había obstaculizado hasta el momento el logro de acuerdos ${ }^{38}$. Se introducía así en el Tratado esa aproximación por etapas que se venía planteando, posibilitando la fijación de esos principios comunes en lugar de un procedimiento único e idéntico para todos los Estados miembros.

De esta forma, el Parlamento Europeo designó a Georgios Anastassopoulos como nuevo ponente para la reforma electoral, que en el informe remitido al Parlamento Europeo proponía como principios comunes $^{39}$ :

- La elección de los diputados del Parlamento europeo por votación de listas según un sistema proporcional, permitiendo a los Estados miembros mantener el tipo de sistema proporcional de su preferencia (D'Hondt, Hare-Niemeyer, Sainte-Lagüe, etc);

- El establecimiento de circunscripciones territoriales obligatorias para las elecciones de 2004, para aquellos Estados miembros con una población superior a 20 millones de habitantes, y que los Estados miembros

32 Corbett, R.; Jacobs, F., Shackleton, M., op. cit., p. 15. Resolución del Parlamento Europeo A3-0381/92), DO C 115/122 de 26 de abril de 1993 (sesión del Parlamento Europeo de 10 de marzo de 1993).

33 Ibid., punto 3.c).

34 Kark., K. S., op. cit., p. 136.

35 Corbett, R.; Jacobs, F., Shackleton, M., op. cit., p. 15.

36 Vid. ap. 38 del Tratado de Ámsterdam de 1997, DO C 340 de 10.11.1997.

37 Anastassopoulos Report, op. cit., p. 13.

38 KarK., K. S., op. cit., p. 137.

39 Anastassopoulos report, op. cit., pp. 7-8 y 16-22. 
pudiesen permitir el voto preferencial (a fin de posibilitar una relación directa y efectiva entre votantes y eurodiputados);

- La introducción (opcional) de un umbral mínimo para la asignación de escaños (barrera electoral) que no excediese del 5\% de los votos emitidos;

- El establecimiento de listas transnacionales, limitado al $10 \%$ de los escaños del Parlamento, que contribuiría a dar a las elecciones europeas una dimensión más europea; $y$,

- La incompatibilidad del mandato de eurodiputado con la de diputado de un Parlamento nacional.

La propuesta fue adoptada por el Consejo, con la aprobación del Parlamento Europeo, adoptándose así la segunda reforma del AEE de $1976^{40}$, si bien dos propuestas fueron excluidas: las listas transnacionales y las circunscripciones territoriales obligatorias ${ }^{41}$. De esta forma, como se ha adelantado, se superaban los problemas que planteaba el establecimiento de un sistema totalmente uniforme y se introducía el concepto de principios comunes y el sistema de representación proporcional.

Así, desde las elecciones de 2004 y 2009 el sistema utilizado en todos los Estados miembros es el sistema proporcional, si bien siguen existiendo diferencias respecto a la determinación del número de circunscripciones, el establecimiento de barreras electorales o umbrales, o el sistema de listas ${ }^{42}$; así como diferentes métodos para calcular la proporcionalidad: D'Hondt, Hare-Niemeyer, Sainte-Lagüe, etc. Diferencias que apenas tienen impacto en el equilibro político del Parlamento Europeo ${ }^{43}$.

Tras la entrada en vigor del Tratado de Lisboa, nuevos informes han continuado trabajando de cara a una reforma electoral para tratar de lograr una mayor uniformidad (no una completa armonización) y un espacio democrático común ${ }^{44}$ : el informe Duff, que mantiene la propuesta del informe Anastassopoulos de introducir listas transnacionales a fin de desarrollar la idea de democracia transnacional o postnacional ${ }^{45}$; y el último informe hasta la fecha, realizado por Hubner y Leinen, que continúa con la idea de fortalecer la dimensión democrática y

40 La primera se llevó a cabo mediante Decisión del Consejo 93/81/Euratom, CECA, CEE. DO L033, de $9 / 2 / 1993$.

41 Decisión del Consejo 2002/772/CE, Euratom, de 25 de junio de 2002 y de 23 de septiembre de 2002. DO L283 de 21/10/2002;

42 Corbett, R.; Jacobs, F., Shackleton, M., op. cit., p. 16.

43 Ibid. p. 18.

44 Alonso de León, S., op. cit., p. 246.

45 El informe no sería votado en pleno, ante la reticencia de los grupos políticos a iniciar una reforma que requeriría una revisión de los Tratados. KARK., K. S., op. cit., p. 182. A este respecto, el Parlamento Europeo adoptaría una resolución sobre las elecciones en 2014 en la que instaba a los partidos políticos europeos a proponer candidatos a la presidencia de la Comisión, quedando así pospuesta la propuesta de listas transnacionales. Vid. Resolución del Parlamento Europeo, de 22 de noviembre de 2012 sobre las elecciones al Parlamento Europeo en 2014 (2012/2829(RSP)), P7-TA(2012)0462, 1. De esta forma, en las elecciones europeas de 2014 se introdujo el sistema de «cabezas de lista», mediante el que los partidos políticos europeos 
transnacional de las elecciones europeas y la legitimidad democrática del proceso decisorio de la Unión ${ }^{46}$.

Tras este último informe, en julio de 2018 el Consejo adoptó la Decisión 2018/994 del Consejo, de 13 de julio de 2018, por la que se modifica el Acta relativa a la elección de los diputados al Parlamento Europeo por sufragio universal directo ${ }^{47}$. Se trata de una reforma técnica, que se centra en fomentar la participación en las elecciones al Parlamento Europeo ${ }^{48}$, y que entrará en vigor una vez ratificada por todos los Estados miembros de conformidad con sus normas constitucionales nacionales, por lo que las elecciones de 2019 se han celebrado según las disposiciones vigentes ${ }^{49}$.

Como puede observarse, aunque no se ha conseguido llegar a un acuerdo global sobre un procedimiento electoral realmente uniforme, gradualmente se ha ido produciendo una cierta convergencia de los sistemas electorales ${ }^{50}$. Pero como señala el Parlamento Europeo en su resolución de noviembre de 2015, las elecciones europeas se siguen rigiendo en su mayor parte por las legislaciones nacionales, la campaña electoral sigue siendo nacional y los partidos políticos europeos no pueden cumplir adecuadamente a formar la conciencia política europea y expresar la voluntad de los ciudadanos ${ }^{51}$.

Un paso más en esta aproximación gradual puede decirse que también se produce con la reciente sentencia del TJUE sobre el caso Junqueras. En la misma, el Alto tribunal de la UE ha confirmado que los Estados miembros siguen siendo los competentes para regular el procedimiento electoral y realizar la proclamación oficial de los resultados electorales ${ }^{52}$, pero señala que la condición de eurodiputado se adquiere desde el momento en que se produce la proclamación oficial de los resultados electorales por el Estado miembro ${ }^{53}$, momento desde el que se reconoce la inmunidad como miembro del Parlamento Europeo ${ }^{54}$. Es decir, la inmunidad se adquiere antes de constituirse la Cámara, para que el elegido pueda desplazarse a recoger su

propusieron a sus candidatos a la presidencia de la Comisión. Para más información al respecto, vid. HoBOLT, S.B., op. cit., pp. 1528-1540.

46 Resolución del Parlamento Europeo, de 11 de noviembre de 2015, sobre la reforma de la ley electoral de la Unión Europea (2015/2035(INL)), P8_TA(2015)0395, ap. 1.

47 DOUE L178, de 16/07/2018. El Parlamento Europeo daba su aprobación al proyecto de Decisión del Consejo mediante su Resolución legislativa de 4 de julio de 2018, Parlamento Europeo, Documento P8_TA(2018)0282.

48 Alonso de LeÓn, S., op. cit., p. 250.

49 Ante la imposibilidad de finalizar el proceso de ratificación con carácter previo a las elecciones de 2019, se acordó enviar una carta al Parlamento y a la Comisión al respecto. Vid. Consejo de la Unión Europea, documento 7686/19, de 22 de marzo de 2019.

50 Tal y como señala la Resolución del Parlamento Europeo, de 11 de noviembre de 2015, ap. J.

51 Ibid. ap. L.

52 No siendo competente el Parlamento Europeo para cuestionar esta proclamación o controlar su adecuación al derecho de la UE. Sentencia del Tribunal de Justicia (Gran Sala) de 19 de diciembre de 2019, asunto C-502/19, ECLI:EU:C:2019:115, ap. 69.

53 Ibid. aps. 71 y 74.

54 Ibid ap. 77. 
acta de eurodiputado ${ }^{55}$. Entendemos que no cambia en esta sentencia de criterio el TJUE con respecto a su jurisprudencia anterior, pues se mantiene que la proclamación de los resultados electorales compete a los Estados miembros ${ }^{56}$ y que el procedimiento electoral está regulado por las disposiciones nacionales ${ }^{57}$. Lo que viene a clarificar el TJUE es el momento de la adquisición de la condición de eurodiputado a efectos de las inmunidades ${ }^{58}$. Algo que, como señala Araceli Mangas, «es claro ahora, no antes ${ }^{59}$, pues con anterioridad no se había pronunciado a este respecto ${ }^{60}$.

55 Por todo ello, concluye que debía haberse levantado la prisión provisional para que Junqueras pudiese desplazarse al Parlamento Europeo y cumplir allí con las formalidades requeridas para recoger su acta, debiendo haber solicitado el tribunal nacional al Parlamento Europeo la suspensión de dicha inmunidad en caso de considerar que debía mantenerse la medida de prisión provisional. Ibid. aps. 90 a 92 . No obstante, deja al tribunal remitente la apreciación de los efectos aparejados a las inmunidades de que goza el Sr. Junqueras. Ibid. ap. 93.

56 Pues se señala que «[...] incumbe a las autoridades nacionales proclamar los resultados determinados con arreglo a las normas nacionales conformes con el Derecho comunitario». Sentencia del Tribunal de Justicia (Sala Cuarta) de 30 de abril de 2009, asuntos acumulados C-397/07 y C-9/08, ECLI:EU:C:2009:275, ap. 74 , conocida como asunto Donnici.

57 Ibid. aps. 45 y 56. Vid., asimismo, Sentencia del Tribunal de Justicia (Sala Segunda) de 7 de julio de 2005, asunto C-208/03 P, ECLI:EU:C:2005:429, conocida como asunto Le Pen, ap. 82.

58 SJUE C-502/09, ap. 81. A este respecto, como señala Germán Teruel, las conclusiones del Abogado General cuestionan las normas nacionales que condicionan la adquisición plena si no se cumplen ciertos requisitos. Teruel, G., «La «euroinmunidad» de Junqueras: un ejemplo de diálogo entre tribunales», Agenda Pública, 12 de enero de 2020.

59 Señala la autora que, si la interpretación y aplicación realizada desde 1979 no planteaba dudas, lo más conveniente habría sido no plantear la cuestión prejudicial. No obstante, pese al pronunciamiento del TJ, señala que no ha habido infracción del derecho de la Unión, pues se trata de un aspecto que el TJUE aclara con esta sentencia, ni invalidez del proceso ante el Supremo pues se trata de un caso ya juzgado y condenado por sentencia firme por unos hechos anteriores a la adquisición de la condición de eurodiputado. Vid. Mangas Martín, A., «Sentencia Europea. Inmunidad de Junqueras. Infinitos daños colaterales», Blog aracelimangasmartin.com, 19 de diciembre de 2019. Efectivamente, finalmente el Tribunal Supremo se ha pronunciado señalando que acepta la nueva doctrina sentada por el TJUE, pero acuerda que no procede la libertad del Sr. Junqueras ni el suplicatorio pues cuando fue proclamado electo el proceso penal ya había concluido y la Sala iniciado el proceso de deliberación, concluyendo que «quien participa en un proceso electoral cuando ya está siendo juzgado, aunque finalmente resulte electo, no goza de inmunidad conforme al derecho nacional. No puede condicionar el desenlace del proceso ni, menos aún, el dictado de la sentencia. Por todo ello, conforme al párrafo primero a) del artículo 9 del Protocolo de Inmunidades, no era ni es necesaria autorización del Parlamento». Auto del Tribunal Supremo (Sala de lo Penal) de 9 de enero de 2020, FJ 5.3.1.

60 En el asunto Le Pen el TJUE abordaba la vacante del escaño del Sr. Le Pen anulado por el Estado francés y en Donnici sobre las facultades del Parlamento Europeo respecto de la verificación de credenciales. Como señala Araceli Mangas, además, el pronunciamiento es coherente con el Acta Electoral, la CDF y los Tratados. En efecto, como recoge la sentencia Donnici «incumbe a las autoridades nacionales proclamar los resultados determinados con arreglo a las normas nacionales conformes con el Derecho comunitario». Pues bien, el art. 10.3 del TUE recoge el derecho de los ciudadanos a participar en la vida democrática de la Unión y el art. 39.2 de la CDF recoge el derecho de sufragio pasivo, que se ven afectados si el diputado electo no puede tomar posesión del cargo. Asimismo, el art. 5.2 del Acta Electoral establece el momento del comienzo del mandato de los eurodiputados, cuyo efecto útil queda afectado si se impide completar los trámites previstos a nivel nacional para tomar posesión del cargo. Estas, y otras disposiciones, fueron puestos de relieve por el abogado del Sr. Junqueras en las observaciones para la vista. Las mismas se encuentran disponibles en https://defensaexili.org/wp-content/uploads/2019/12/Vista-Cas-Junqueras.pdf. Aunque las disposiciones nacionales, por tanto, sean las que determinen los requisitos que se han de cumplir para tomar posesión del cargo, los mismos deben ser conformes con el Derecho de la Unión y, por consiguiente, entendemos que el razonamiento del TJUE es coherente al establecer que la condición de eurodiputado se adquiere desde antes 
Puede concluirse, por tanto, que la aproximación que el Parlamento Europeo ha mantenido en todos los informes examinados ha sido ir armonizando de forma efectiva en todos los Estados miembros el procedimiento de las elecciones al Parlamento Europeo, ante la clara dificultad de lograr un consenso para la adopción de un procedimiento electoral uniforme ${ }^{61}$. $Y$ tras los avances realizados, las últimas reformas adoptadas buscan ese avance hacia unas elecciones con una dimensión más europea, en las que se refuerce la legitimidad democrática y transnacional.

\section{EL SISTEMA ELECTORAL BRITÁNICO PARA LAS ELECCIONES AL PARLAMENTO EUROPEO: DEL TRADICIONAL SISTEMA MAYORITARIO A LA ADOPCIÓN DE UN SISTEMA DE TIPO PROPORCIONAL}

Como se ha adelantado en el apartado anterior, uno de los obstáculos para la adopción de un procedimiento electoral uniforme fue el mantenimiento hasta 1999 del sistema mayoritario en el Reino Unido: el denominado first past the post system $(\text { FPTP })^{62}$. En 1999 el Reino Unido reformaba la ley que regulaba las elecciones al Parlamento Europeo introduciendo el sistema D'Hondt con listas cerradas y bloqueadas ${ }^{63}$, lo que posibilitó reformar el AEE en 2002 para introducir el sistema de representación proporcional en las elecciones al Parlamento Europeo ${ }^{64}$. Sin embargo, el debate sobre la conveniencia de utilizar otro sistema para las elecciones al Parlamento Europeo no era la primera vez que se planteaba. Ya a raíz de la celebración de las primeras elecciones directas al mismo el gobierno británico estudió la posibilidad de no utilizar el característico FPTP, como se examina a continuación.

\section{El debate sobre el sistema a adoptar para las primeras elecciones directas a la Asamblea Europea}

Como es de sobra conocido, en un sistema mayoritario una mínima variación de votos puede producir una importante variación en el número de escaños

de constituirse la Cámara y que el impedir que se cumpla uno de los requisitos para tomar posesión del cargo afecta a la inmunidad y, por tanto, debería haberse solicitado el suplicatorio a dichos efectos.

61 Resolución del Parlamento Europeo, de 11 de noviembre de 2015, ap. F.

62 Como es sabido, se trata de un sistema en el que una mínima variación en votos puede producir una importante variación en el número de escaños atribuidos, alterando el equilibro político en un Parlamento. Por ejemplo, Corbett, Jacobs y Shackleton señalan cómo hasta 1994 los liberal-demócratas no consiguieron ningún escaño pese a ser uno de los partidos liberales más grandes con un 19.5 por ciento del voto en 1984 . Corbett, R.; Jacobs, F., Shackleton, M., op. cit., p. 17.

63 Art. 3 European Parliamentary Elections Act 1999. Ver, asimismo, Garrote de Marcos, M., «La reforma del sistema electoral británico», Teoría y realidad constitucional, $\mathrm{n}^{\circ} 28,2011$, p. 532.

64 Artículo 1 ap. 2 Decisión del Consejo 2002/772/CE,Euratom. 
atribuidos. En el caso del sistema electoral mayoritario empleado en Reino Unido dicha variación puede ser importante a la hora de formar un gobierno y es, en efecto, uno de los efectos que busca dicho sistema: proporcionar patrones claros de gobierno y oposición, primándose por tanto la conformación de un gobierno sobre los posibles efectos distorsionadores que el sistema electoral puede ocasionar en la representación de los partidos políticos en el parlamento ${ }^{65}$. Para las elecciones a la Asamblea Europea, en cambio, la cuestión no se centraba en formar un gobierno o lograr unas mayorías estables, sino que en la misma todos los puntos de vista dentro de un Estado miembro estuviesen representados de forma justa. Por ello, a raíz del acuerdo en septiembre de 1976 para la celebración de las primeras elecciones directas a la entonces Asamblea Europea, ya se planteaba la necesidad de debatir en el Reino Unido el sistema electoral a empelar y los partidarios de la representación proporcional vieron en las mismas un campo de ensayo de sus propuestas con vistas a una posible reforma del sistema electoral a nivel interno ${ }^{66}$. Ahora bien, como destaca Huber, el debate respecto al sistema a adoptar para las elecciones a la Asamblea Europea se encontró con cinco problemas principales que ponían en peligro la adopción de la legislación necesaria a tiempo ${ }^{67}$ :

- la oposición dentro del partido laborista a la pertenencia a las Comunidades Europeas, que por lo tanto manifestaron una amplia oposición a las elecciones directas a la Asamblea Europea;

- la demanda por el partido nacionalista escocés y por el partido nacional de Gales de representación en la Asamblea Europea, en lugar de ser considerados solo dentro del contingente británico en proporción a Inglaterra;

- la debilidad del gobierno laborista en la Cámara de los Comunes que obligó al gobierno a llegar a un pacto con los liberales en marzo de 1977 para asegurar la mayoría en la Cámara ${ }^{68}$. Pacto en el que se contemplaba la adopción de un sistema de representación proporcional para las elecciones directas a la Asamblea Europea, que para los liberales constituía una prioridad, acordándose que la legislación específica se presentaría en la legislatura en curso y que el gobierno realizaría una «consulta» entre los dos

65 Huber, CH. H., «Approaches to European Elections», en Sasse, Brew, Georgel, Hand, Huber and van den Berghe, The European Parliament: Towards a Uniform Procedure for Direct Elections, European University Institute, Florence: Badia Fiesolana, 1981, p. 153.

66 Ibid.

67 Ibid. pp. 150-153

68 El llamado «Lib-Lab pact» de 1977-78, negociado entre el gobierno laborista de J. Callaghan (que afrontaba una posible moción de censura) y el líder del partido liberal D. Steel, consiguió mantener casi un año y medio un gobierno en minoría en un momento de crisis económica. HADDON, C., «A Brief History of the Lib-Lab Pact, 1977-78» en HAZELL, R. - PAUN, A. (eds.) Making minority government word: Hung parliaments and the challenges for Westminster and Whitehall, Institute for Government, The Constitution Unit, December 2009, p. 20. 
partidos al respecto ${ }^{69}$, manteniéndose en todo caso la libertad de voto en el partido laborista en los Comunes a la hora de votar el sistema electoral ${ }^{70}$; el debate sobre la reforma electoral, surgido a raíz del proceso de devolution en Escocia y Gales, que se entremezcló con el debate sobre las elecciones directas a la Asamblea Europea y, en concreto, con lo que respecta al sistema electoral a elegir ${ }^{71} ; \mathrm{y}$, los plazos para la adopción de la legislación pertinente, pues el proyecto de ley para la devolution había bloqueado el calendario parlamentario y dificultaba al gobierno la aprobación de la European Elections Bill a tiempo, sin poner en peligro la fecha fijada por el Consejo de Ministros de las Comunidades ${ }^{72}$.

Aparte de las problemáticas señaladas, por lo que respecta al íter que seguiría la adopción del sistema electoral para las elecciones a la Asamblea Europea puede resumirse de la siguiente forma. En febrero de 1976, el gobierno británico presentaba un libro verde ${ }^{73}$ en el que se abordaban aspectos como el tamaño de la representación británica, la fecha de las elecciones y otras cuestiones que se estaban discutiendo a nivel comunitario. El mismo dio lugar al primer debate sobre el principio de elecciones directas a la Asamblea Europea, que fue apoyado por los portavoces de laboristas, conservadores y liberales ${ }^{74}$. Unos meses más tarde, se nombraba una comisión especializada para examinar propuestas de cara a esas primeras elecciones directas, entre ellas la cuestión del sistema electoral a utilizar. Comisión que recomendó el mantenimiento del sistema mayoritario tradicional del Reino Unido ${ }^{75}$, si bien su informe no llegó a debatirse en la Cámara ${ }^{76}$.

69 Ibid.

70 Huber, CH. H., op. cit., p. 151.

71 Por el miedo a que la decisión del mismo a uno de estos niveles (para Escocia y Gales, así como para la Asamblea Europea) derivase en una campaña para cambiar también el sistema electoral para Westminster. Ibid. p. 152.

72 Ya que, si para las elecciones a Westminster el procedimiento para fijar las circunscripciones uninominales llevaba normalmente hasta dos años, la no adopción del sistema mayoritario implicaría que el tiempo para acordar las circunscripciones regionales se acortaría considerablemente. Ibid.

73 Gay, O., «The European Parliament Elections Bill [Bill No 4 of 1998-9]», Research Paper 98/102, House of Commons, 1 December 1998, p. 7.

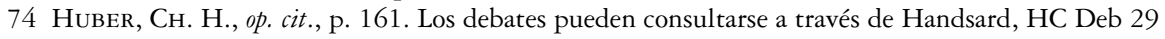
March 1976 vol 908 cc900-1036 y HC Deb 30 March 1976 vol 908 cc1119-240.

75 La decisión, señala Huber, se adoptó principalmente con vista a la fecha prevista para la celebración de las elecciones a la Asamblea Europea y el interés de conservadores y liberales de mantener el sistema mayoritario. Huber, CH. H., op. cit., p. 154-155. Consideró, además, la comisión los cambios ulteriores que serían necesarios ante la esperada armonización de los sistemas electorales nacionales en el futuro. MuLDERs, L. A M., «Conference Report: Sixteenth Leiden-London Meeting, Direct Elections and the Future of the European Parliament», Common Market Law Review vol. 15, num. 1, 1978, p. 70. Los tres informes de la comisión y sus recomendaciones fueron tenidos en cuenta por el gobierno, dando respuesta a los mismos en el libro blanco que se examina a continuación. White paper on Direct Elections to the European Assembly, Cmnd 6768 (April 1977), p. 4, ap. 5.

76 GAY, O., «The European Parliament Elections Bill [Bill No 4 of 1998-9]», op. cit, p. 7. 
Un año más tarde, en 1977, el Gobierno británico publicaba un libro blanco titulado «Direct Elections to the European Assembly» en el que nuevamente se planteaba la cuestión del sistema electoral a utilizar. El mismo, se señalaba, planteaba una cuestión de gran dificultad para el Reino Unido por su característico sistema electoral, de amplia tradición y bien entendido por los votantes y los partidos polí$\operatorname{ticos}^{77}$. No obstante, se recordaba asimismo la mencionada tendencia del sistema a ocasionar considerables variaciones a la hora de la atribución de los escaños y la problemática que ello plantearía a nivel de la representatividad en la Asamblea Europea $^{78}$. A este respecto, se observaba cómo mientras los efectos del sistema mayoritario podían ser una ventaja para las elecciones al Parlamento británico (pues se está eligiendo un gobierno), no eran tan deseables en el caso de las elecciones europeas ${ }^{79}$. Así, se planeaba cómo alguna de estas dificultades podrían superarse (o mitigarse, al menos) adoptando un sistema de representación proporcional para las elecciones a la Asamblea Europea, ya que la misma no constituía una legislatura ni su función era proporcionar un gobierno ${ }^{80}$. Se reflejaba, de esta forma, una cierta apertura a la consideración de este sistema, en cumplimiento con el pacto firmado con los liberales ${ }^{81}$. En concreto, el libro blanco contemplaba tres posibilidades principales:

\section{- el mantenimiento del sistema mayoritario ${ }^{82}$;}

- la adopción de un sistema de lista regional abierta que permitiese a los electores escoger entre los distintos candidatos ${ }^{83}$, que acercaría al Reino Unido a los sistemas utilizados en otros Estados miembros y aseguraría una mayor proporcionalidad ${ }^{84} ; \mathrm{y}$,

- la adopción del sistema de voto único transferible en circunscripciones plurinominales, utilizado ya desde 1973 en Irlanda del Norte ${ }^{85}$.

Se enfatizaba, en todo caso, las dificultades de un cambio en el sistema y la importante innovación constitucional que supondría abandonar el tradicional

77 White paper on Direct Elections to the European Assembly, p. 6, ap. 8.

78 Ibid. p. 7, ap. 14.

79 Pues, por el número de escaños a repartir en ese momento (81) podía arrojar resultados más desproporcionales y magnificar la diferencia entre la composición de los Comunes y la representación del Reino Unido en la Asamblea Europea. Ibid. Vid., asímismo, Ministry of JustiCE, The governance of Britain: review of voting systems, the experience of new voting systems in the United Kingdom since 1997, 2008, p.81.

80 White paper on Direct Elections to the European Assembly, p. 7, ap. 15.

81 Huber, CH. H., op. cit., p. 155.

82 White paper on Direct Elections to the European Assembly, pp. 10-14.

83 El libro blanco analizaba también la posibilidad de un sistema de representación proporcional de lista nacional sin preferencia de voto, pero se señalaba que era preferible el de lista regional abierta. Ibid., anexo B, pp. $21-24$.

84 Ibid., p. 7, aps. 16 y 17

85 Ibid., anexo C, pp. 25-.27. 
FPTP, lo que requería un amplio debate en el Parlamento ${ }^{86}$. El principal problema a partir de este momento pasaba a ser la elección del sistema electoral, no el principio en sí de la realización de elecciones directas a la Asamblea Europea —aunque en los debates dicha cuestión siguió resurgiendo—— ${ }^{87}$.

El libro blanco sería debatido en la Cámara de los Comunes los días 20 y 25 de abril de $1977^{88}$, en los que como señala Huber resultó evidente que como un amplio número de parlamentarios esperaban que se desarrollase un sistema uniforme para las elecciones Europeas, mostraron su oposición tanto a la introducción de un nuevo sistema como a cualquier iniciativa de cara a la adopción de la representación proporcional ${ }^{89}$. De los debates puede observarse que la mayoría de laboristas y conservadores defendían el mantenimiento del sistema mayoritario ${ }^{90}$, apoyando la adopción del sistema proporcional los liberales y solo unos pocos miembros de los dos partidos principales y los partidos nacionalistas ${ }^{91}$. Por otra parte, pueden observarse asimismo las distintas posturas a favor y en contra con respecto al establecimiento de un sistema de representación proporcional, algunas coincidentes con las ventajas y desventajas reflejadas en el propio libro blanco presentado por el gobierno.

Por lo que respecta a los argumentos en contra, procedentes de las filas de laboristas y conservadores, puede decirse que principalmente están relacionados con la distancia del sistema de representación proporcional y sus requisitos con respecto del tradicional sistema mayoritario utilizado en Reino Unido y la forma en la que se configuran elementos básicos del mismo como, por ejemplo, la base personal de su representación, la forma en que se determinan las circunscripciones o el poder del elector a la hora de elegir al candidato ${ }^{92}$. En los mismos se

86 Ibid., p. 5 , ap. 7.

87 El Sr. John Davies así lo recordaba en el debate de 20 de abril de 1977, llamando la atención a que la cuestión sobre el principio de elecciones directas estaba ya superada. Handsard, HC Deb 20 April 1977 vol. 930 cc200-333, cc. 211. Aunque algunos parlamentarios, como Stokes o Heffer, continuaron mostrando sus reservas u oposición a la celebración de elecciones directas. Ibid., cc. 300 y 256-263. Por el contrario, otros parlamentarios apoyaron claramente la realización de elecciones directas y la adopción de un sistema de representación proporcional, como el ex Primer Ministro Heath, que señalaba el Reino Unido debería dar un paso y liderar. Ibid., cc. 229. O Fairgrieve que pedía que Reino Unido dejase de ser el freno en Europa y pasase a ser un motor. Ibid., cc. 268.

88 Handsard, HC Deb 20 April 1977 vol 930 cc200-333 y HC Deb 25 April 1977 vol 930 cc735-960

89 Huber, Сн. H., op. cit., p. 158. Ver, por ejemplo, la postura de Heffer, que señalaba que, aunque se mantuviese el sistema mayoritario, tampoco importaría porque «sólo duraría cinco años»; o Shersby, que destacaba que no había garantía de que no hubiese que cambiar de nuevo el sistema cuando se celebrasen elecciones conforme a un procedimiento uniforme en toda la Comunidad. Handsard, HC Deb 20 April 1977 vol. 930 сc200-333, сc. 261 у 313 respectivamente.

90 Huber, CH. H., op. cit., p. 162.

91 Ibid. p. 163.

92 Como señala M. Garrote, los distritos uninominales favorecen la vinculación más directa y personal del candidato con el electorado de su circunscripción, permitiendo al mismo tiempo a este una mayor independencia de la cúpula de los partidos. Garrote de Marcos, M., op. cit., p. 527. Trabajo en el que puede 
refleja la preocupación por la alteración de estos elementos que produciría la adopción del sistema proporcional. Así, por ejemplo, el laborista Shersby señalaba que el mismo sería contrario al concepto de circunscripción uninominal y esa relación directa y personal entre candidato y elector, dando mucho poder a los partidos políticos ${ }^{93}$; y el conservador Rodgers apuntaba a que se destruiría la responsabilidad personal del parlamentario frente a su circunscripción ${ }^{94}$.

En cuanto a los argumentos a favor de adoptar un sistema proporcional, hay que destacar la intervención del ex Primer Ministro Eduard Heath en el debate celebrado el 20 de abril, en el que destaca las principales desventajas de la utilización del tradicional sistema mayoritario, en especial los efectos que tendrían las circunscripciones que arrojaría dicho sistema ${ }^{95}$. O el también conservador Fairgrieve, que señalaba que con el sistema mayoritario en determinadas regiones partidos como el liberal no obtendrían representación, algo «patentemente ridículo» ${ }^{96}$. Otros argumentos señalaban la poca representatividad del sistema ${ }^{97}$.

Como resultado del debate, unos meses más tarde, el 24 de junio de 1977 se publicaba un proyecto de ley, la European Assembly Elections Bill ${ }^{98}$, que seguía estrechamente lo avanzado en el libro blanco pero ofrecía solamente la opción entre dos sistemas electorales: un sistema proporcional de lista regional abierta ${ }^{99}$ o el mantenimiento del FPTP si así se decidía posteriormente por resolución de los Comunes ${ }^{100}$. Se cumplía así con el pacto con los liberales ${ }^{101}$.

El proyecto sería debatido en segunda lectura en julio de 1977, debate en el que básicamente se mantuvieron los argumentos ya expuestos durante los debates del libro blanco ${ }^{102}$. Pero tendría que ser reintroducido al comienzo de

encontrarse un excelente análisis del sistema electoral británico, sus intentos de reforma y el referéndum al respecto celebrado en 2011.

93 Recordaba que FPTP era un sistema que estaba relacionado íntimamente con el concepto de circunscripción, en el que cada miembro elegido tiene una especial relación con su propia circunscripción, lo que es una ventaja. Handsard, HC Deb 20 April 1977 vol 930 cc200-333, cc. 312-313.

94 Que también destacaba que el FPTP era el sistema al que los ciudadanos estaban acostumbrados. Ibid., cc. 285-286.

95 La mayoría ganadora en las mismas sería demasiado pequeña, los partidos pequeños no tendrían posibilidad de obtener representación, se producirían amplias distorsiones, etc. Ibid., cc. 233-234. Vid., asimismo, Huber, CH. H., op. cit., p. 163.

96 Handsard, HC Deb 20 April 1977 vol 930 cc200-333, cc. 267-268.

97 Aspecto señalado por Hunt, Owen o el propio Heath. Ibid. cc. 316, 209 y 234 respectivamente.

98 Bill 142 de 1976/77.

99 En el que cada elector en una región electoral tuviese un único voto que pudiese emitir por un candidato designado y los escaños a repartir por cada región fuesen asignados según un sistema de representación proporcional basado en la fórmula D'Hondt que se delineaba en la Parte II del proyecto de ley. Parte I, cláusula 3, Bill 142 de 1976/77.

100 Ibíd.

101 Huber, CH. H., op. cit., p. 160.

102 El debate y votación en segunda lectura (394 síes frente a 147 noes) puede consultarse en Handsard, HC Deb 07 July 1977 vol 934 cc1436-569. Huber, Ch. H., op. cit., p. 164. 
la siguiente sesión (1977-78), siendo finalmente adoptado en tercera lectura el 16 de febrero de 1978, optándose por el mantenimiento del FPTP para Reino Unido (contra la recomendación del Gobierno) y estableciendo el sistema de voto único transferible para Irlanda del Norte ${ }^{103}$. Tras el paso por la Cámara de los Lores, la European Assembly Elections Act quedaba finalmente aprobada el 4 de mayo de $1978^{104}$.

De esta forma, hubo de esperarse hasta los años noventa y a la reforma introducida por el Tratado de Ámsterdam, que modificaba el artículo 138.3 del TCE para introducir el criterio de principios comunes para las elecciones al Parlamento Europeo para que finalmente en el Reino Unido se modificase el sistema de elección al mismo.

\section{La reforma: el abandono del sistema mayoritario}

El debate sobre la reforma del sistema electoral para las elecciones al Parlamento Europeo y sobre la conveniencia del mantenimiento del sistema mayoritario resurge en la década de los noventa. Durante la misma, los Liberal-demócratas comenzaron a presionar para la introducción del sistema proporcional y Lord Bonham-Carter llegaría a presentar un proyecto de ley que contemplaba el sistema de voto único transferible, con Escocia y Gales como única circunscripción e Inglaterra dividida en nueve circunscripciones ${ }^{105}$. Se examina en el presente apartado el cambio en el panorama político que posibilitaría la reforma y que daría lugar a la European Parliamentary Elections Act de 1999.

\subsection{El cambio en el panorama político}

Como se ha adelantado, en la década de los noventa vuelve a resurgir en Reino Unido el debate sobre la reforma electoral, pero no sólo en relación al sistema de elección al Parlamento Europeo sino más ampliamente, incluyendo

103 Debe señalarse, que laboristas y conservadores habían dado libertad de voto a este respecto. El resto de cláusulas e itinerarios relacionados con el sistema de lista regional incluidos en el proyecto de ley fueron rechazados por la Cámara. HC Deb 16 February 1978 vol 944 cc762-847, cc. 763. El proyecto sería aprobado por 159 votos a favor y 45 en contra. Ibid. cc. 846. Vid., asimismo, MinisTry of Justice, op. cit., p. 81; Gay, O., op. cit., p. 13; Miller, V., «The European Parliament (Representation) Bill, Bill 7 of 2002/03», Research Paper 02/78, House of Commons, 4 December 2002, p. 7.

104 HL Deb 04 May 1978 vol 391 cc363-7. La regulación final del sistema de elección quedaba fijada en el artículo 3 de la European Assembly Elections Act de 1978 de la siguiente forma: «Assembly elections shall be held and conducted in accordance with the provisions of Schedule 1 to this Act (with Schedule 2) under the simple majority system (for Great Britain) and the single transferable vote system (for Northern Ireland)».

105 Ministry of Justice, op. cit., p. 82; Gay, O., op. cit., p. 18. 
incluso la reforma al sistema de Westminster ${ }^{106}$. El cambio de postura del partido laborista ${ }^{107}$, junto con el pacto con los liberal-demócratas de cara a las elecciones de 1997, tendría una indudable influencia en el proceso.

Con anterioridad a 1997, puede decirse que la postura de los laboristas con respecto a la reforma electoral era indeterminada o difícil de definir; los conservadores siempre se habían mostrado firmemente en contra de todo cambio; y los liberal-demócratas habían abogado siempre por la representación proporcional y el sistema de voto único transferible (en particular para Escocia y Gales ${ }^{108}$. Pero tras perder los laboristas cuatro elecciones seguidas se produjeron, como señala Dunleavy, las condiciones para el cambio. En concreto, señala el citado autor diversos factores que confluyen y que llevan al cambio en el sistema de elección al Parlamento Europeo: el movimiento de reforma constitucional surgido desde comienzos de los años noventa; el papel del grupo Charter 88; el pacto entre laboristas y liberal demócratas que llevaría a la victoria de los primeros en las elecciones de 1997; y las distintas facciones y posiciones existentes dentro del propio partido laborista ${ }^{109}$.

En concreto, el partido laborista establecería en 1990 un grupo de trabajo sobre el sistema electoral presidido por Raymond Plant que, en el informe final presentado en mayo de 1993, recomendaba un sistema de lista regional para las elecciones al Parlamento Europeo ${ }^{110}$ bien mediante la emisión del voto para una lista de partido, bien posibilitando al votante seleccionar el orden de los candidatos. Informe en el que de nuevo se reflejan algunas de las ideas ya plasmadas en el libro blanco de 1977 que vendrían a justificar la no necesidad de mantener el mismo sistema electoral para las elecciones al Parlamento Europeo y a Westminster (destacándose, nuevamente, el hecho de que a través de las mismas no surge un Gobierno). Sistema de lista regional que aproximaría el sistema británico a los utilizados en otros Estados europeos ${ }^{111}$.

El partido laborista aceptaría la recomendación y, antes de las elecciones de 1997, el sistema de lista regional para las elecciones al Parlamento Europeo en Inglaterra sería propuesto por el Comité Consultivo conjunto sobre reforma electoral que laboristas y liberal-demócratas habían creado para considerar elementos

106 Tanto a nivel de los distintos partidos como fuera de estos surgieron diversos grupos para la promoción del debate sobre la reforma electoral. El partido laborista contaba con los grupos Labour Campaign for Electoral Reform y First Past the Post, los conservadores con el grupo Conservative Action for Electoral Reform, y los liberal-demócratas con el grupo DAGGER (Democrat Action Group for Gaining Electoral Reform). Fuera de los paridos, la Electoral Reform Society y los grupos Charter 88 y Voting Reform, también promovieron dicho debate. GAY, O., «Voting systems: The Jenkins Report», Research paper 98/112, House of Commons, 10 December 1998, p. 13.

107 Cambio no solo en materia electoral, sino también en otras áreas constitucionales. Ibid., p. 12.

108 Dunleavy, P., «Assessing how far Charter 88 and the constitutional reform coalition influenced voting system reform in Britain», Parliamentary Affairs, Volume 62, Issue 4, October 2009, p. 630.

109 Ibid.

110 GAY, O., «Voting systems: The Jenkins Report», op. cit., p. 12.

111 Gay, O., «The European Parliament Elections Bill [Bill No 4 of 1998-9]», op. cit., p. 19 
comunes en sus programas constitucionales de reforma ${ }^{112}$. La intención era introducir el mismo para las elecciones de junio de $1999^{113}$.

El pacto entre laboristas y liberal demócratas surgido del Comité consultivo conjunto mencionado tuvo un importante efecto y posibilitó que los laboristas ganasen las elecciones obteniendo los dos tercios de los escaños en la Cámara de los Comunes (418 escaños, estando la mayoría en 178) con un 44 por ciento del voto. Tras este triunfo, por tanto, los laboristas no tenían ninguna excusa para no proceder rápidamente con las reformas prometidas, entre ellas la del sistema de elección al Parlamento Europeo ${ }^{114}$. Triunfo que tendría efecto asimismo en las distintas posturas dentro de las propias filas laboristas al respecto (reformistas, centristas y ultras) $)^{115}$.

\subsection{La European Parliamentary Elections Bill}

Tras la victoria laborista en las elecciones de 1997 se presentaba al Parlamento británico el proyecto de ley para las elecciones al Parlamento Europeo de 1997 (European Parliamentary Elections Bill 1997-98) que proponía un sistema en el que el votante podría elegir bien un partido a nivel regional (sistema de lista cerrada), bien un candidato independiente ${ }^{116}$. Para la distribución de escaños se proponía la fórmula D'Hondt y el sistema de voto único transferible para Irlanda del Norte se mantenía ${ }^{117}$.

112 Ministry of Justice, op. cit., p. 82. Otro de los acuerdos alcanzados por el Comité fue la creación de una comisión para considerar una alternativa proporcional al sistema mayoritario para los Comunes (la Comisión Jenkins) y el sometimiento a referéndum de la opción que la misma escogiese. BLACKBURN, R.; FOX, R.; GAY, O.; MAER, L., Who Governs? Forming a coalition or a minority government in the event of a hugh Parliament, Hansard Society \& Study of Parliament Group 2010, p. 17. El llamado pacto Cook-Maclennan puede considerarse el documento en materia de reforma constitucional más amplio jamás acortado entre partidos en el Reino Unido y todos los elementos contenidos en el mismo, con la excepción del referéndum sobre los sistemas de votación, fueron implementados tras la victoria de los laboristas en las elecciones de 1997. DuNLEAVY, P., op. cit., pp. 624-625.

113 Si bien el partido laborista no se comprometió con ningún calendario específico para su implementación, aunque en julio de 1997 el Ministro del Interior, Jack Straw, anunciaba que las elecciones de 1999 se llevarían a cabo mediante un sistema regional de lista proporcional. Miller, V., op. cit., p. 7.

114 Dunleavy, P., op. cit., pp. 632-635.

115 Dunleavy analiza la evolución de las mismas en la fase previa a las elecciones de 1997, en la que no se detecta ninguna postura ganadora; una segunda fase post-electoral (1997-2000) en la que respecto a la constitución del Parlamento Escocés, la Asamblea Nacional de Gales y la Greater London Authority se llega a un acuerdo unánime para un cambio radical; y una tercera fase también post-electoral (1998-2001) en la que el cambio radical visto para los nuevos órganos no tiene eco en la reforma al sistema de elección de Westminster, que dejaba de ser una preocupación principal para los laboristas. Ibid. pp. 632-640.

116 Cláusula 1.3 (1) y (2) European Assembly Elections Bill 1997-98. Puede consultarse en: https:// publications.parliament.uk/pa/cm199899/cmbills/004/1999004.htm. Vid, asimismo, GAY, O., «The European Parliament Elections Bill [Bill No 4 of 1998-9]», op. cit., pp. 27-28.

117 Cláusula 1.3 (3) a (8) y cláusula $1.3 \mathrm{~A}$. 
Las cuestiones de la reforma que planteaban mayor preocupación eran la utilización de la fórmula D'Hondt y sus efectos para los partidos pequeños cuando el recuento se hace en base regional, la pérdida de identidad en las circunscripciones al establecerse un sistema regional de lista, que los resultados no fuesen proporcionales al asignarse distinto número de escaños a las circunscripciones, y el protagonismo que pasaban a adquirir los partidos políticos en la determinación de las listas ${ }^{118}$.

El debate en el Parlamento se centró en el tipo de sistema de lista a utilizar, siendo la preferencia del Gobierno el sistema de lista cerrada ${ }^{119}$. El Secretario de Estado defendió la utilización de la fórmula D’Hondt y volvió a señalar la diferencia fundamental entre el Parlamento Europeo y el Parlamento británico, pues en las elecciones al primero no se trata de elegir un gobierno, por lo que las características de los sistemas de representación proporcional y sus consecuencias (posibles resultados no-proporcionales y gobiernos no estables) no eran de aplicación ${ }^{120}$. El Sr. Beith, de los liberal-demócratas, destacaba los injustos resultados de seguir aplicando el sistema mayoritario para las elecciones al Parlamento Europeo ${ }^{121}$, o la falta de adecuación a la realidad de seguir argumentando que el mantenimiento de dicho sistema trataba de asegurar ese vínculo sagrado entre el elector y su representante $^{122}$. David Drew, miembro del grupo Charter 88, daba la bienvenida a la reforma y la aproximación del secretario de Estado, recomendando un sistema de lista regional que combinase tanto el voto por un partido como la posibilidad de que el elector pudiese escoger al candidato que considerase que más quiere que le represente ${ }^{123}$. Por el contrario, Brian Mawhinney, de la oposición, entendía que el nuevo sistema sería peor que el anterior y que destruiría el vínculo entre circunscripciones y representantes individualmente elegidos, impidiendo a los votantes elegir a sus representantes individuales ${ }^{124}$. Como puede observarse, por tanto, vuelven a surgir los mismos argumentos (tanto a favor como en contra) que ya habían surgido en 1977 y que han sido examinados en el punto anterior.

Debido a los desacuerdos entre la Cámara de los Comunes y la de los Lores por lo que respeta a la cuestión de las listas abiertas o cerradas, pues esta última

118 GAY, O., «The European Parliament Elections Bill [Bill No 4 of 1998-9]», op. cit., pp. 35-36.

119 Ibid. pp. 41 y ss.

120 HC Deb 25 November 1997 vol 301 cc803-77, cc. 804.

121 Así, por ejemplo, señalaba cómo en 1984 los conservadores habían obtenido 45 escaños con el 38.3 por ciento del voto, mientras que los laboristas solo 32 con un 4 por ciento menos de votos cuando, en ese momento, los escaños correspondientes al Reino Unido eran una quinta parte del Parlamento por lo que la falta de representación de los votos emitidos en Reino Unido podía tener un efecto significativo en el equilibro político. Ibid. cc. 833 .

122 Pues destacaba la falta de conocimiento de los ciudadanos de sus representantes al Parlamento Europeo. Ibid.

123 Sistema que denominaba «part-one list approach» y que consideraba más justo y representativo. Ibid. cc. 836 .

$124 \mathrm{Ibid}$. cc. 818. Por el contrario, Burden señalaba que esto no era cierto y que el sistema de «miembro adicional» permitiría mantener dicho vínculo. Ibid. cc. 830. 
introdujo una enmienda para la utilización de listas abiertas, el primer intento de aprobar el proyecto de ley fracasó ${ }^{125}$. La ausencia de acuerdo implicaba que el proyecto no podía ser aprobado, aunque en la Cámara Alta no se rechazase en segunda o tercera lectura. Por ello, el Gobierno anunció que reintroduciría el proyecto en la siguiente sesión bajo las Parliament Acts ${ }^{126}$ y, así, se presentaba la European Parliamentary Elections Bill 1998-99 con mínimas modificaciones ${ }^{127}$. Se mantenía, por tanto, el sistema regional de lista para Gran Bretaña con el método D'Hondt para la distribución de escaños, y el sistema de voto único transferible para Irlanda del Norte ${ }^{128}$. Finalmente, los Lores rechazaron dar una segunda lectura al proyecto, por lo que se presentó para la sanción real bajo el procedimiento previsto por las mencionadas Parliament Acts el 14 de enero de $1999^{129}$. De esta forma, la European Parliamentary Elections Act de 1999 quedaba aprobada.

\section{CONCLUSIONES}

Es de sobra conocida la dificultad de lograr acuerdos a la hora no solo de establecer sino también de reformar cualquier aspecto del Derecho electoral, en especial los elementos del sistema electoral. Como se ha examinado en el presente trabajo, se trata de una problemática de la que no han escapado ni el Parlamento Europeo ni el Parlamento británico.

Por lo que respecta al sistema de elección del Parlamento Europeo, los distintos informes que han abordado la cuestión y que se han examinado muestran desde un primer momento la problemática señalada, a la que además se une la dificultad de poner de acuerdo a distintos Estados miembros con sus distintas tradiciones constitucionales e idiosincrasias. La evolución analizada también muestra la tensión que ha existido desde los propios orígenes del proceso de integración y a lo largo de toda su evolución entre «supranacionalidad» e «intergubernamentalidad» y la distinta visión existente en Parlamento Europeo y Consejo respecto

125 Un análisis detallado de los debates en la Cámara de los Lores en GAY, O, «The European Parliament Elections Bill [Bill No 4 of 1998-9]», op. cit., pp. 45-48. En concreto, la enmienda proponía un sistema de lista abierta siguiendo el modelo finés y fue aprobada por 165 votos a favor y 140 en contra. HL Deb 20 October 1998 vol 593 cc1316-36, cc. 1333.

126 Se trata de dos leyes aprobadas en 1911 y 1949 que limitan los poderes de la Cámara de los Lores: la primera limitando su poder de veto; la segunda reduciendo el tiempo que puede «retrasar» la aprobación de un proyecto de dos a un año. Una breve explicación de las mismas se encuentra a través de la página web del parlamento británico: https://www.parliament.uk/about/how/laws/parliamentacts/. Para una explicación más detallada de la problemática que planteaba el uso de este procedimiento puede consultarse WINETROBE, B. K., «Lords Reform: The Legislative Role of the House of Lords», Research Paper 98/103, House of Commons, 1 December 1998, pp. 9-12.

127 Gay, O., «The European Parliament Elections Bill [Bill No 4 of 1998-9]», op. cit., p.48; MiLLER, V., op. cit., p. 8.

128 Gay, O., «The European Parliament Elections Bill [Bill No 4 of 1998-9]», op. cit., p. 48.

129 Miller, V., op. cit., pp. 7-8. 
del sistema a adoptar. Es lo que ha determinado que los avances en la materia hayan sido especialmente lentos y que finalmente no dispongamos de un procedimiento electoral uniforme sino de unos principios comunes.

En el caso del Reino Unido, como se ha examinado, dos han sido los aspectos que imposibilitaron en un primer momento la adopción de un sistema proporcional para las elecciones al Parlamento Europeo y que más resistencia plantearon en 1999 cuando finalmente se logró establecer el mismo: el tradicional euroescepticismo del partido conservador y dentro de las propias filas del partido laborista, y la fuerte reticencia a abandonar el tradicional sistema mayoritario, pese que desde un primer momento se reconocían los efectos distorsionadores del mismo en la representación de los partidos en el Parlamento Europeo y la no necesidad de mantener el mismo sistema para su elección — pues no estaba en juego la formación de un gobierno como a nivel nacional- El fuerte arraigo, puede decirse, del tradicional FPTP y sus elementos básicos (la base personal de la representación y el poder del elector a la hora de elegir al candidato especialmente), centraron los debates sobre el sistema para las elecciones al Parlamento Europeo, tanto durante los que llevarían a la adopción de la European Assembly Elections Act de 1978, como los que llevarían a su reforma en 1999.

En resumen, la dificultad de alcanzar un consenso a nivel de los Estados miembros para establecer un procedimiento uniforme derivó en la fijación simplemente de unos principios comunes. Y aunque con el tiempo se ha ido hacia una mayor convergencia de los sistemas electorales, aplicándose un sistema de elección proporcional en todos los Estados miembros, las elecciones europeas se siguen rigiendo en su mayor parte por las legislaciones nacionales y sigue habiendo un amplio margen de apreciación para los Estados miembros y diferencias entre ellos, como por ejemplo la determinación de las circunscripciones o las fórmulas para el reparto de escaños. También siguen faltando elementos que permitirían aproximar las elecciones al Parlamento Europeo a unas verdaderas elecciones europeas, como el hecho de que las mismas se realizasen el mismo día en todos los Estados miembros o la fallida propuesta de listas transnacionales, y que permitirían en parte crear o avanzar en la idea de un demos europeo. Una mayor armonización en estos puntos puede que llegue con el tiempo, atendiendo a la tradicional evolución del proceso de integración europeo de ir realizando las necesarias reformas paso a paso y llegando a consensos, así como el papel que el TJUE también desempeña en el desarrollo de la integración.

$$
* * *
$$

Title: The European Parliament Electoral Procedure: a reflection of the historical double vision of the integration process and the difficulty for consensus achievement.

AbSTRACT: The European Parliament is the most democratic institution of the institutional framework of the UE, elected since 1979 by direct universal suffrage. The bistory of the construction of the European Parliament's electoral procedure is clear reflection of the European integration process evolution and the 
different views with regard to it (intergovernmentalism vs. supranationalism) Process where the reach of consensus is not always easy and, therefore, requires progress to be made stepwise. Consensus that is even more difficult to attain when talking about the essential elements of an electoral procedure and, in particular, of the electoral system to adopt. Elements in which the different constitutional traditions and understandings of the Member States have a great influence, as the British case clearly exemplifies with the strong opposition that arose against the abandonment of their traditional majoritarian system.

Resumen: El Parlamento Europeo es la institución más democrática de todas las que integran el marco institucional de la UE, elegido desde 1979 directamente por sus ciudadanos. La historia de construcción del procedimiento de elección del Parlamento Europeo es un fiel reflejo de la bistoria de la evolución del proceso de integración y de las dos diferentes visiones a la hora de avanzar en el mismo (intergubernamentalidad vs. supranacionalidad). Proceso en el que las dificultades para llegar a consensos han requerido que los avances se realicen paso a paso, muchas veces de forma lenta. Consensos aún más complejos de lograr cuando de lo que se trata es de acordar los elementos claves de un procedimiento electoral y, más en concreto, el sistema electoral a adoptar. Aspectos en los que tiene una importante influencia las distintas tradiciones constitucionales y visiones que respecto de los sistemas electorales tienen los distintos Estados miembros, como bien ejemplifica el caso británico y las reticencias que surgieron para el abandono de su tradicional sistema mayoritario para las elecciones al Parlamento Europeo. evolution.

KEY WORDS: European Parliament, Uniform Electoral Procedure, Electoral System, UK, historical

Palabras clave: Parlamento Europeo, Procedimiento electoral uniforme, sistema electoral, Reino Unido, evolución histórica.

FECHA DE RECEPCIÓN: 19.12.2019

FECHA DE ACEPTACIÓN: 19.02.2020 